\title{
Tenth graders' problem-solving performance, self-efficacy, and perceptions of physics problems with different representational formats
}

\author{
Ching-Sui Hung ${ }^{1,2}$ and Hsin-Kai $\mathrm{Wu}^{1,3, *}$ \\ ${ }^{1}$ Graduate Institute of Science Education, National Taiwan Normal University, \\ P.O. Box 97-27, Taipei 11699, Taiwan \\ ${ }^{2}$ Taipei Municipal Heping High School, 100 Wolong Street, Da-an District, Taipei 10671, Taiwan \\ ${ }^{3}$ Faculty of Education, University of Johannesburg, \\ Kingsway Avenue, Auckland Park, Johannesburg 2006, South Africa
}

(Received 6 September 2017; published 5 November 2018)

\begin{abstract}
Numerical and symbolic representations are used extensively in physics problems. However, relatively little is understood about how students respond to these two representational formats when they are solving problems. This study examined the effect of the representational format (numeric vs symbolic) on the problem-solving performance, self-efficacy, and perceptions of students. Both quantitative and qualitative data were collected during this two-stage study: the first stage involved 100 10th graders solving problems that were in either the numerical or symbolic format, while in the second stage a subset of the students (6 from each group) solved physics problems in another format and were subsequently interviewed. The results showed that the numerical group significantly outperformed the symbolic group. Moreover, boys reported significantly higher self-efficacy than girls, even though no gender difference was found in their performance. In the problem-solving process, there were significant differences in how the interviewees performed when executing the plan and evaluating the solution between the two formats. We also found that most students perceived the symbolic problems as being more difficult than the numeric ones. These findings provide insights into better ways for teachers to support how students learn about physics problems in the numerical and symbolic representations.
\end{abstract}

DOI: 10.1103/PhysRevPhysEducRes.14.020114

\section{INTRODUCTION}

Problem solving is an essential and common task in physics education [1]. Teachers take advantage of problem solving to introduce new physics principles, integrate related physics concepts, apply related knowledge to new situations, and evaluate the understanding that students have of newly learned knowledge in physics. Previous research has shown that some factors (e.g., gender, prior knowledge, metacognitive skills, topics, and the representational format of problems) and their particular combinations can affect the performance and competence of students in problem solving [2-6].

Among the factors, the representational format is the main focus of this study. A physics concept or principle cannot be expressed, understood, or communicated without using representations such as words, equations, symbols, diagrams, or graphs. The use of multiple representations to

\footnotetext{
*hkwu@ntnu.edu.tw

Published by the American Physical Society under the terms of the Creative Commons Attribution 4.0 International license. Further distribution of this work must maintain attribution to the author(s) and the published article's title, journal citation, and DOI.
}

provide related information in different formats can help physicists to explore and work with physics systems; similarly, they can also support students to understand physics phenomena and the underlying principles [7-9].

Research concerning representational formats and physics problem solving has focused on verbal or linguistic, diagrammatic, pictorial, graphic, symbolic, and mathematical forms [2-5,10-12]. Some studies have explored the effects of different representations on the problem-solving strategies employed by students $[2,10]$ and their performance, error types, and learning perceptions $[4,5,12]$. Their results showed that different representational formats can trigger distinct strategies and error types, and further influence how students perform. For example, students tended to perform calculations or manipulate symbols rather than employ qualitative strategies when facing problems with an equation or other types of mathematical representations [2-4,13]. Other studies have explored how students approach physics problems [14] and how they apply or understand related knowledge (e.g., mathematical) while solving physics problems $[15,16]$. These studies have yielded possible reasons and mechanisms underlying differences in performance, strategies, or difficulties between students. 
However, the aforementioned studies provided little information about the impacts of different representational formats on problem-solving processes. Particularly in practice, symbolic formats are often used with numerical ones in the same problem, but they may produce different effects on the problem-solving processes as well as students' performances. Additionally, neither did the previous studies take a close look at the problem-solving steps in which different representations may result in marked differences in students' performances. Thus, one of the main purposes of this study was to determine the effects of representational formats (numerical and symbolic) on the problem-solving performance of students, and the associated processes. Furthermore, previous research in physics education has not examined how various factors (e.g., selfefficacy and gender) interplay with representational formats and problem-solving performances. To fill the research gap, we collected both quantitative and qualitative data to explore the factors of self-efficacy, gender, and perceptions in relation to representational formats and problem-solving performances in order to provide a more comprehensive view of problem solving in physics.

Different types of representation have different pedagogical affordances in scientific processes [17], and mathematical representations are used extensively to present the quantitative and generalized relations between physics variables; indeed, they are the dominant language used to express the principles or laws of physics. However, mathematics as a language of physics must be interpreted and understood in physics in a particular way different from that in mathematics itself $[18,19]$. Students need to understand this in order to avoid difficulties when they are solving tasks or problems related to mathematics $[16,20]$.

In this study, we concentrated our attention on two mathematical representations employed to express specific and generalized physics variables: numerical and symbolic formats (Table I). Both types of representation are widely used in practice, and yet solving physics problems with them inevitably involves addressing arithmetic or algebra problems of varying difficulty. Research in mathematics education has confirmed that students encounter difficulties in algebra and also make the same mistakes at different ages, such as expecting a numerical answer rather than a correct algebraic expression (e.g., " $2 n$ " or
" $7 a+2 b$ "), and misinterpreting the meaning of letters and variables [21-23].

Would solving algebra problems in physics be easier or more challenging? Below we draw on learning theories to address this question.

\section{A. Theoretical foundation}

Information-processing models and cognitive-load theory are prominent theories related to problem solving and learning [1,24]. In the former theory, Newell and Simon [25] described short-term memory [(STM), also called working memory] and long-term memory as two important components of the human informationprocessing system. The STM is small and can only process a few discrete items at any given time, while the latter is almost unlimited. If problem solvers want to access information that is stored in long-term memory, it must be activated and brought into STM. If the amount of problem information or knowledge needed exceeds the STM capacity, the solver may encounter cognitive overload. Accordingly, schema activation and automation that can optimize the capacity of STM are two critical learning mechanisms [24].

Sweller [24] reported that a schema "is a cognitive construct that organizes the elements of information according to the manner with which they will be dealt" (p. 296). If students are familiar with the subject matter and become more proficient, their knowledge will be organized into schemas and some skills will become automatic, and a solution will be found immediately when they can activate an existing schema to solve a problem [1]. Sweller [24] further indicated that the intrinsic cognitive load is related to the degree of element interactivity of the learning materials. If there is a high degree of interaction, many schemas involving the elements must be learned simultaneously, which will result in a high intrinsic cognitive load and make the material difficult to learn or understand.

Figure 1 can be used to illustrate the element interactivity and schemas involved in solving question 3 in the study. In the step of executing the plan and evaluating solutions, students have to deal with at least 5 substeps. Each substep consists of a different number of elements that are associated with learners' knowledge. For instance, in the numerical format, substep 3 involves at least five elements: (i) $F_{\text {Jack }}=m_{1} a_{1}$, (ii) $m_{1}=60(\mathrm{~kg})$, (iii) $a_{1}=3\left(\mathrm{~m} / \mathrm{s}^{2}\right)$,

TABLE I. An example problem in the numerical and symbolic formats.

\begin{tabular}{lc}
\hline \hline Numerical format & Symbolic format \\
\hline $\begin{array}{l}\text { A 3-kg object is falling with a constant velocity in water, and the } \\
\text { buoyancy force exerted on it is } 10(\mathrm{~N}) \text {. What is the magnitude of } \\
\text { the friction exerted on the object? [the acceleration due to } \\
\left.\text { gravity is } 10\left(\mathrm{~m} / \mathrm{s}^{2}\right)\right]^{\mathrm{a}}\end{array}$ & $\begin{array}{c}\text { An } M(\mathrm{~kg}) \text { object is falling with a constant velocity in water, and } \\
\text { the buoyancy force exerted on it is } B(\mathrm{~N}) \text {. What is the magnitude } \\
\text { of the friction exerted on the object? [the acceleration due to } \\
\left.\text { gravity is } g\left(\mathrm{~m} / \mathrm{s}^{2}\right)\right]^{\mathrm{a}}\end{array}$ \\
\hline \hline
\end{tabular}

${ }^{\mathrm{a}}$ The scoring rubrics and ideal problem solution of the example problem are presented in Appendix A. 


\begin{tabular}{|c|c|}
\hline Question 3 in the numerical format: & Question 3 in the symbolic format: \\
\hline $\begin{array}{l}\text { Jack of mass } 60 \mathrm{~kg} \text { and Jill of mass } 40 \mathrm{~kg} \text {, } \\
\text { on a frictionless horizontal surface, push } \\
\text { each other. If Jack accelerates at } 3\left(\mathrm{~m} / \mathrm{s}^{2}\right) \\
\text { in that moment, find the acceleration of Jill } \\
\text { at the same time. }\end{array}$ & $\begin{array}{l}\text { Jack of mass } M \text { and Jill of mass } m \text {, on a } \\
\text { frictionless horizontal surface, push } \\
\text { each other. If Jack accelerates at a in } \\
\text { that moment, find the acceleration of Jill } \\
\text { at the same time. }\end{array}$ \\
\hline $\begin{array}{l}\text { Step 3: Executing the plan and evaluating } \\
\text { solutions }\end{array}$ & $\begin{array}{l}\text { Step 3: Executing the plan and evaluating } \\
\text { solutions }\end{array}$ \\
\hline $\begin{array}{l}\mathrm{F}_{\text {Jack }}=\mathrm{m}_{1} \mathrm{a}_{1}=60 \times 3=180(\mathrm{~N}) \\
\mathrm{F}_{\text {Jill }}=180=\mathrm{m}_{2} \mathrm{a}_{2}=40 \times \mathrm{a}^{\prime} \\
\mathrm{a}^{\prime}=4.5\left(\mathrm{~m} / \mathrm{s}^{2}\right)\end{array}$ & $\begin{array}{l}\mathrm{F}_{\text {Jack }}=\mathrm{m}_{1} \mathrm{a}_{1}=\mathrm{Ma} \\
\mathrm{F}_{\text {Jill }}=\mathrm{m}_{2} \mathrm{a}_{2}=\mathrm{Ma}=\mathrm{ma} \\
\mathrm{a}^{\prime}=\frac{M}{m} \mathrm{a}\end{array}$ \\
\hline
\end{tabular}

\begin{tabular}{ll} 
Sub-steps involved in Step 3: & Sub-steps involved in Step 3: \\
$\begin{array}{ll}\text { (1) Newton's third law, } F_{\text {Jack }}=F_{\text {Jill }} & \text { (1) Newton's third law, } F_{\text {Jack }}=F_{\text {Jill }} \\
\text { (2) Newton's second law, } F=m a & \text { (2) Newton's second law, } F=m a \\
\text { (3) } F_{\text {Jack }}=m_{1} a_{1}=60 \times 3=180(N) & \text { (3) } F_{\text {Jack }}=m_{1} a_{1}=M a \\
\text { (4) } F_{\text {Jill }}=m_{2} a_{2}=180=40 a ' & \text { (4) } F_{\text {Jill }}=m_{2} a_{2}=m a ' \\
\text { (5) the acceleration of Jill: } 180=40 a^{\prime} & \text { (5) the acceleration of Jill: Ma }=m a ' \\
a^{\prime}=180 / 40=4.5\left(\mathrm{~m} / \mathrm{s}^{2}\right) & a^{\prime}=M a / m\end{array}$ \\
\hline
\end{tabular}

FIG. 1. Elements in step 3 of question 3.

(iv) $m_{1} a_{1}=60 \times 3=180$, and (v) the unit of force: $\mathrm{kg} \mathrm{m} / \mathrm{s}^{2}=\mathrm{N}$. These elements are interacted and connected to each other and the step could not be completed if any of the elements is missed. The intrinsic cognitive load could be high to 10th graders. Additionally, some of these elements could be further organized into a schema. Depending on students' prior knowledge and mathematical skills, some students' schemas may be more integrated and can be activated automatically when they solve the problem.

Although the elements of the same substep in the symbolic format are similar to those in the numerical format, to 10th graders, the elements in the symbolic format include more unknown variables or unfamiliar formats of mathematical solutions, such as (ii) $m_{1}=M$, (iii) $a_{1}=a$, and (iv) $m_{1} a_{1}=M a$. In this case, the schemas related to solving numerical problems may be more integrated and already existed, and the mathematical skills required to solve equations with numerical variables may be automatic. However, when solving symbolic problems, 10th graders may encounter difficulty in executing the elements and equations [22]. They may lack appropriate schemas to identify solutions or fail to apply a prior schema to the unfamiliar situations in these substeps [26]. Their cognitive load may also increase when they attempt to construct new schemas about these steps or to integrate new information into an existing schema. Additionally, due to the complex interactions between the elements involving manipulation of symbols and their small amount of prior knowledge, students could experience a higher intrinsic cognitive load [24]. Therefore, it can be argued that solving symbolic problems in physics is more challenging than solving numerical ones.
A similar inference can be made based on a resourcesbased perspective [27]. This perspective describes knowledge transfer on the basis of the "conceptual" and "epistemological" resources of students and explains why students who have acquired the related knowledge and skills fail to apply them in some contexts [1]. It can also be used to illustrate how students use and comprehend mathematics symbols and equations in physics. By taking this perspective, Tuminaro [15] and Tuminaro and Redish [16] provided a cognitive framework to explain how students apply mathematics when facing physics problems. They indicated that the problem-solving performance and approaches of students are influenced by their mathematical resources, the reasoning strategies they employ, and how they interpret the situation. These mathematical resources are "abstract knowledge elements - the cognitive tools involved in mathematical thinking and problem solving" (p. 7, [15]), such as knowledge about counting, symbolic forms, and equations. The inappropriate use of mathematical resources [28] and reasoning strategies, an incorrect interpretation of situations, or an inappropriate combination thereof would result in a poor problemsolving performance. These studies based on the resource's perspective have also implied that students may experience more difficulties in solving symbolic than numerical problems because the former requires the use of more complex mathematical resources, symbol manipulation, interpreting the information expressed by symbols, and appropriately evaluating the unexpected answers. For example, in the fifth substep about "the acceleration of Jill" in Fig. 1, compared to the numerical solution, the one in the symbolic format 
involves a more complex symbolic form and requires more sophisticated strategies to interpret [15].

Drawing upon the theories discussed above, we hypothesized that students perform better on numerical problems than on symbolic ones (hypothesis 1).

\section{B. Problem-solving process}

In order to investigate how the numerical and symbolic formats affect the performance of students when they are solving physics problems, this study simplified the steps suggested by Heller and Hollabaugh [29] to analyze the problem-solving process as follows: (i) describing the physics, (ii) planning the solution, and (iii) executing the plan and evaluating solutions.

The first step may involve students generating visual diagrams, identifying target variables, and providing simplified physics descriptions of the problem. The second step may involve the students selecting specific physics principles or equations containing the target variables, and indicating the conditions or rationales that they have used to select them. Finally, in the third step the students may construct and solve the mathematical equations and connect unknown variables with known ones by inserting the known quantities into equations to calculate the unknown ones.

In the three steps, the effects of problem formats on students' performances could be different. Regarding the first step, previous studies have found that students seldom employ visual diagrams to solve problems, instead of regarding it as a strategy used only by teachers [30] or a separate task from the problem-solving process. Even when they do employ representations and descriptions, they seldom combine them with the mathematical part of the problem [2]. In other words, for some students, representing a problem to describe the physics may not be part of their problem-solving schema [26] or they have difficulty integrating mathematic information into the existing schema. It can be predicted that students could ignore or fail to finish the first step regardless of the problem formats.

With respect to the second step, different problem formats may activate different schemas to support students to plan the solution. Numerical variables in physics problems may be familiar and understandable to students; they could search for prior schemas of relevant variables and mathematical procedures [26]. On the other hand, symbolic variables (e.g., $m$ and $F$ ) could remind them of physics equations (e.g., $F=m a$ ) and activate a schema of relevant physics principles. Thus, students could benefit from either type of representational format used in the problems during the second step.

However, the third step is most closely related to the mathematical ability of students. Torigoe and Gladding [31] found that confusion about symbolic meanings and misinterpreting physics equations with algebraic representations were key reasons for failure in physics compared to numerical problems, even among university students. Tenth graders (as analyzed in the present study) also find manipulating symbolic equations a serious challenge due to their small amount of experience with algebra [22]. Additionally, the existing schemas for solving problems and evaluating solutions in a numerical form may not be activated or applicable to symbolic problems [26]. We therefore hypothesized that students perform significantly better on numerical problems than on symbolic ones in the third step (hypothesis 5). Finally, we analyze their responses in these three steps to reveal the effects of using the symbolic or numerical format in each step.

\section{Self-efficacy and problem solving}

This study also investigated other factors in order to comprehensively identify the factors related to problemsolving performance [15] and their interplay. First, selfefficacy as a key element of student affect or beliefs has yet to be comprehensively explored in physics education research [1]. According to Bandura [32], "perceived selfefficacy is a judgment of capability to execute given types of performances" (p. 309). Self-efficacy is a task-specific construct that is significantly related to the academic performance of students [32,33] and can predict their motivation and learning [34].

Most studies concerning the influences of self-efficacy on problem solving have focused on mathematical problem solving [6,35-37], with few studies addressing the relations between physics problem solving and self-efficacy [38]. In related research, Meltzer [5] found that students who answered correctly had different levels of confidence in successfully solving physics problems with different representations: in a circuits quiz, the students had lower confidence in solving graphical and mathematical problems than verbal ones. However, the confidence metric used in that study differed from self-efficacy and was rated after solving the problems. Because of the critical role played by self-efficacy, and in order to fill the gap in the related research, the present study explored how the self-efficacy of students differs when they are solving physics problems in the two formats. Another question also emerges: with which format do students have higher self-efficacy when solving two isomorphic physics problems?

Bandura $[39,40]$ also argued that the perceived selfefficacies were constructed by interpreting information from four sources: mastery experiences, vicarious experiences (the experiences of observing others perform similar tasks), social persuasions (the verbal and nonverbal judgments of others), and physiological arousal (the emotional state individuals experience while engaging in an action or task). Mastery experiences were recognized as the most influential factor and the strongest predictor of self-efficacy [41]. The 10th graders included in the present study had many opportunities to solve numerical problems, such as in homework, learning material, or textbook exercises. 
However, they had insufficient experiences in solving symbolic problems and interpreting the meaning of symbols. They probably also struggled with algebra related to physics problems in the symbolic format [22]. We therefore hypothesized that students have higher selfefficacy when solving numerical problems than symbolic ones (hypothesis 2).

\section{Gender, self-efficacy, and problem solving}

Gender is another factor that could be related to the selfefficacy and problem-solving performance of students. Gender disparities are nowadays receiving increasing attention in physics teaching and learning due to females exhibiting a low rate of involvement and engagement with physics [42-46]. In particular, most studies of the gender gap in physics concepts or performance in university have found that men significantly outperform women $[47,48]$.

However, among students in elementary and secondary schools, Hyde and colleagues $[49,50]$ suggested that how students perform in science and mathematics is better reflected or characterized by gender similarities than by gender differences. For example, they used the data in reports of the National Assessment of Educational Progress (NAEP) to illustrate that the gender difference in science achievement remains small to negligible from 4th grade to 12th grade [effect size $(d)=0.12$ to 0.11 ]. They also found that the mathematical ability of students related to science showed either no significant gender difference or only a small effect size. In addition, it is noteworthy that crossnational research has indicated differences between cultures being greater than those between the genders [e.g., studies of the performance of fifth graders in mathematical word problems [49] and the Programme for International Student Assessment (PISA) 2015 (p. 267) [51]]. PISA 2015 showed that there was no significant gender difference among 15-year-old students in Taiwan (approximately 10th grade) in mathematics performance (p. 197), while there were only slight gender differences among top performers (p. 80) and low-achieving students (p. 79) in science.

Together, these studies imply that high school could be the key stage at which the gender gap in physics increases. By exploring gender differences in high-school students' problem solving performances, this study could deepen current understanding about the gender gap in physics education.

Additionally, other factors may be involved in the relation between gender and science achievement. Previous studies have indicated that self-efficacy can mediate the effect of gender and prior experiences on academic achievement [37]. Self-efficacy might be useful for predicting how students perform and for explaining the gender difference between students who have similar achievement levels [37,39,42]. In fact, according to the PISA report in 2012, girls had much lower science and mathematics self-efficacy even though the gender differences were very small in science and problem solving [52]. We therefore hypothesized that self-efficacy when solving physics problems is higher for boys than for girls (hypothesis 4), while there is no gender difference between boys and girls in problem solving regardless of the representational format (hypothesis 3).

Regarding the interaction effect between gender and the representational format on self-efficacy and problemsolving performances, this study cannot propose any hypothesis owing to the limited amount of literature and mixed results reported in the literature. So far little research in physics education has investigated the relationships between gender, self-efficacy, and problem solving at the high-school level. Yet, studies in mathematics education could shed a light on this issue because the ability and selfefficacy in mathematics are pivotal for solving physics problems in the study. For example, Else-Quest, Hyde, and Linn [53] analyzed the data from the 2003 round of the Trends in International Mathematics and Science Study (TIMSS) in which five content domains (number, algebra, measurement, geometry, and data) were included to assess mathematics achievement. Among the five content domains, girls outperformed boys slightly but significantly in algebra; there was no significant gender difference in number; finally, boys and girls performed similarly overall. However, boys reported statistically significant higher self-confidence in mathematics.

Similarly, in PISA 2012 [54], overall, girls had lower self-efficacy than boys in both mathematics and science. Yet, the PISA results further suggested that the gender gap depended on the type of problem or situation students faced. For example, when students performed tasks similar to some steps required to solve numerical problems, such as solving a linear (e.g., $3 x+5=17$ ) or a quadratic equation [e.g., $2(x+3)=(x+3)(x-3)$ ], no gender differences in self-efficacy were observed. On the other hand, when mathematics problems were presented in contexts related to stereotypical gender roles (e.g., calculating the petrolconsumption rate of a car), the gender differences in selfefficacy were striking [52]. These mixed results suggest that there may be an interaction between the type of problem, gender, and self-efficacy. As little is understood about such interaction, the results of this study could extend current understanding by examining the main and interaction effects of the representational format and gender on the self-efficacy of students in solving physics problems as well as their problem-solving performance.

\section{E. Perception and problem solving}

The third factor explored in this study was perception. Students play a prominent and central role in the context of education, and their perceptions of the teaching materials or a learning program can directly influence or be reflected in their learning outcomes $[30,55]$. The significant relations among the perceptions of students, their performance, and 
the strategies they select have also been confirmed $[30,55,56]$. Although solving physics problems in different formats is a common task in both the classroom and homework, there is only scarce research information on how students perceive the two formats. Therefore, this study applied an exploratory approach to this factor by using qualitative methods, and no hypothesis was proposed due to the exploratory nature of the investigation.

Taken together, this study aimed at understanding how the self-efficacy, gender, and perceptions of students influence the problem-solving processes that they apply to physics problems in either the numerical or symbolic format. The results offer valuable insights into how to design effective physics instruction methods that could improve the self-efficacy and problem-solving performance of students.

\section{F. Research questions and hypotheses}

This study focused on the problem-solving performance of high-school students, for several reasons. Docktor and Mestre [1] indicated that most research studies of physics problem solving involve university students. However, problem solving is also a common and crucial task in high-school physics. High-school students have far less experience of algebra and of extracting physics information from mathematical symbols than do university students [15]. In order to expand the understanding of how highschool students solve problems, we selected 10th graders as the participants in the present study, which employed a mixed-method design. The research questions guiding this study and the associated hypotheses were as follows:

(i) Does the representational format of a physics problem and gender affect the self-efficacy of students in solving physics problems as well as their problemsolving performance?

Hypothesis 1: Students perform better on numerical problems than on symbolic ones.

Hypothesis 2: Students have higher self-efficacy when solving numerical problems than symbolic ones.

Hypothesis 3: There is no difference between boys and girls in physics problem solving regardless of the representational format.

Hypothesis 4: Boys have higher self-efficacy when solving physics problems than do girls.

(ii) How do the numerical and symbolic representational formats affect the performance of students in the problem-solving process?

Hypothesis 5: In the third step of executing the plan and evaluating the solution, students perform significantly better on numerical problems than on symbolic ones.

(iii) What impacts do different representational formats have on solving physics problems, according to the perceptions of students? How do students perceive the difficulties in solving physics problems in the numerical and symbolic formats?

The lack of literature meant that no hypothesis was formulated for the third question. Semistructured interviews were performed to collect information from which some findings would emerge $[57,58]$.

\section{METHODS}

\section{A. Participants and procedures}

This study employed both quantitative and qualitative methods, and was conducted at a public senior high school (grades 10-12) in central Taiwan. The research design, procedures, and participants are shown in Fig. 2. Three 10th-grade classes totaling 100 students (56 girls and 44 boys; average age 16 years) taking a basic physics course participated in the study. The main reason for selecting 10th graders was that they had learned physics for 2 years in junior high school, so they had already developed a conceptual understanding of kinematics and Newton's laws. All of the participants were taught by the first author using the same teaching method and materials with different representations. This study was carried out 1 month later after the related physics concepts of onedimensional kinematics and Newton's law had been taught.

The research design comprised two stages. Each participant was first randomly assigned to either a numerical or symbolic group. The numbers of students in the numerical group in the three classes were 18 (of a total of 33 students), 18 (of a total of 35 students), and 16 (of a total of 32 students), and the other students were assigned to the symbolic group. After completing the self-efficacy questionnaires, the students solved problems that were in either the numerical or symbolic format. Based on their midterm physics examination scores, the 100 10th graders were then divided into high-achieving $(n=33$, mean score $=81.5)$, moderate-achieving $(n=34$, mean score $=71.0)$, and low-achieving $(n=33$, mean score $=52.1)$ groups. We selected 3 high-achieving and 3 low-achieving students from each group, so that 12 students ( 6 girls and 6 boys)

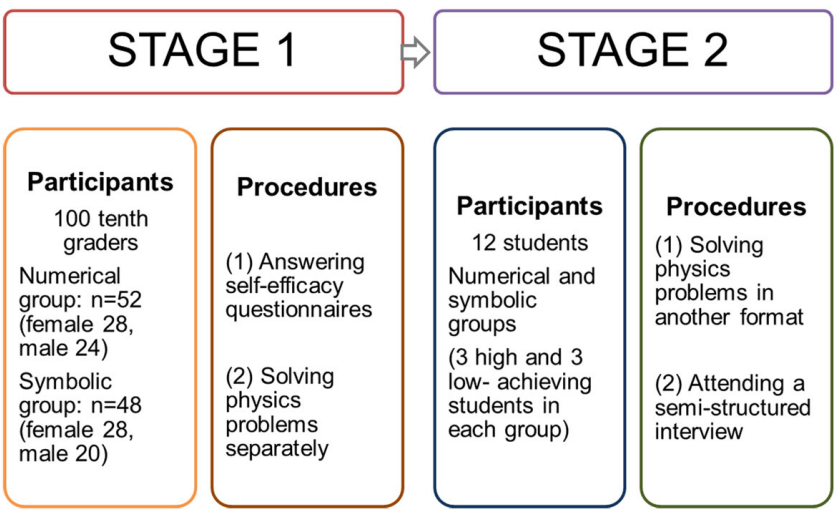

FIG. 2. Procedures and participants in the study. 
TABLE II. Research instruments and their reliability and validity.

\begin{tabular}{|c|c|c|c|}
\hline Research instrument & No. of items & Reliability & Validity \\
\hline Physics problem-solving test (numerical format) & 6 & Test-retest reliability $r=0.71$ & $\begin{array}{l}\text { Content validity } \\
\text { Criterion-related validity } r=0.58^{\mathrm{b}}\end{array}$ \\
\hline Physics problem-solving test (symbolic format) & 6 & Test-retest reliability $r=0.69$ & $\begin{array}{l}\text { Content validity } \\
\text { Criterion }^{\mathrm{a}} \text {-related validity } r=0.63^{\mathrm{b}}\end{array}$ \\
\hline Self-efficacy questionnaire & 6 & Consistency reliability $\alpha=0.91$ & Construct validity \\
\hline
\end{tabular}

${ }^{\mathrm{a}}$ Criterion was school midterm examination scores.

${ }^{\mathrm{b}} p<0.05$

participated in the second stage of the study. In the second stage they solved physics problems in another format and subsequently participated in a semistructured interview. The time interval between the two stages was about 3 weeks in order to reduce the practice effect.

\section{B. Data collection}

\section{Physics problem-solving tests in the numerical or symbolic format}

The first and second instruments consisted of six isomorphic physics problems posed in either the numerical or symbolic format (Table II). According to Singh [59], isomorphic problems require the same physics principle to solve them. All of the problems covered concepts in onedimensional kinematics or Newton's laws.

Because 10th graders in Taiwan are generally familiar with multiple-choice questions but have little experience of writing a problem-solving process in detail, in the two tests we provided the students with written prompts to remind them of the three steps involved in the problem: (i) describing the physics, (ii) planning the solution, and (iii) executing the plan and evaluating solutions.

Two experts, one professor, and one experienced physics teacher reviewed the items of the two tests to ensure that their content and the related physics concepts were appropriate for 10th graders. Additionally, we collected the midterm examination scores of the students for the same topics (one-dimensional kinematics and Newton's laws) to establish the criterion validity of the problem-solving tests. Significant correlations were found between the midterm examination scores and the problem-solving scores for the numerical and symbolic formats, and the coefficients of the criterion-related validity (Pearson's $r$ ) were 0.58 for the numerical format and 0.63 for the symbolic format (Table II). Furthermore, in order to gain the test-retest reliability, two 10th-grade classes in another senior high school were randomly assigned to the numerical group $(n=36)$ and the symbolic group $(n=34)$. These students took the tests twice with a time interval of 10-14 days. The test-retest reliability coefficients (Pearson's $r$ ) were 0.71 for the numerical format and 0.69 for the symbolic format.

Finally, these two tests were administered as physics problem-solving tasks in stage $1(n=100)$ and stage 2 $(n=12)$ to assess the performance and problem-solving processes of the students.

Each test used in stage 1 included six questions. The written responses of the students were graded according to their completeness and correctness. Appendix A shows the scoring rubrics and sample answers. When a student provided correct and complete answers in the steps 1 and 2, he or she would receive 2 points for each step. Because step 3 involved more substeps, the highest score in this step was 6 points. In total, each question was worth 10 points and the full score of the test was 60 . The scoring rules emphasized the process of developing solutions quantitatively and were similar to those of the midterm examination. After calculating the total score of an examination paper, we expressed it as the percentage of the maximum possible score. The average scores represented the problem-solving performance of students; they are presented in Table III. Finally, two coders who had majored in physics and

TABLE III. Scores for the self-efficacy of students in solving physics problems and their problem-solving performance.

\begin{tabular}{|c|c|c|c|c|c|c|c|c|c|c|}
\hline & & \multicolumn{3}{|c|}{ Numerical group } & \multicolumn{3}{|c|}{ Symbolic group } & \multicolumn{3}{|c|}{ Total } \\
\hline & & $\begin{array}{c}\text { Girl } \\
(n=28)\end{array}$ & $\begin{array}{c}\text { Boy } \\
(n=24)\end{array}$ & Total & $\begin{array}{c}\text { Girl } \\
(n=28)\end{array}$ & $\begin{array}{c}\text { Boy } \\
(n=20)\end{array}$ & Total & $\begin{array}{c}\text { Girl } \\
(n=56)\end{array}$ & $\begin{array}{c}\text { Boy } \\
(n=44)\end{array}$ & Total \\
\hline Self-efficacy & $\begin{array}{l}\text { Mean } \\
(\mathrm{SD})\end{array}$ & $\begin{array}{l}4.85 \\
(1.69)\end{array}$ & $\begin{array}{l}5.60 \\
(2.09)\end{array}$ & $\begin{array}{c}5.19 \\
(1.90)\end{array}$ & $\begin{array}{l}4.64 \\
(2.24)\end{array}$ & $\begin{array}{l}5.96 \\
(2.49)\end{array}$ & $\begin{array}{l}5.19 \\
(2.41)\end{array}$ & $\begin{array}{c}4.74 \\
(1.97)\end{array}$ & $\begin{array}{l}5.76 \\
(2.26)\end{array}$ & $\begin{array}{c}5.19 \\
(1.90)\end{array}$ \\
\hline $\begin{array}{c}\text { Problem-solving } \\
\text { performance }\end{array}$ & $\begin{array}{l}\text { Mean } \\
(\mathrm{SD})\end{array}$ & $\begin{array}{l}40.50 \\
(21.45)\end{array}$ & $\begin{array}{c}45.79 \\
(22.12)\end{array}$ & $\begin{array}{l}42.94 \\
(21.71)\end{array}$ & $\begin{array}{c}21.29 \\
(16.27)\end{array}$ & $\begin{array}{c}23.90 \\
(18.86)\end{array}$ & $\begin{array}{c}22.37 \\
(17.25)\end{array}$ & $\begin{array}{c}30.89 \\
(21.21)\end{array}$ & $\begin{array}{c}35.84 \\
(23.25)\end{array}$ & $\begin{array}{c}33.07 \\
(22.15)\end{array}$ \\
\hline
\end{tabular}


science education discussed the scoring rules and independently analyzed 50 student responses, and achieved an interrater reliability coefficient of 0.85 .

\section{Self-efficacy questionnaire}

Bandura [32] suggested that a scale of perceived selfefficacy must be connected to the specific domain of functioning that is the target of interest. Namely, perceived self-efficacy should be measured by how participants rate their own confidence in their ability to execute the required activities when they are presented with items describing task demands. Based on this definition, the self-efficacy questionnaire used in the present study included six items tailored to each problem. At the beginning of the questionnaire the students were instructed to "rate your degree of confidence as a number from 0 to 10 " and an example item was shown as follows: "Please rate how certain you are that you can solve the physics problem" [32]. Then, before solving the physics problems in either a numerical or symbolic format, the students viewed each problem for a short time (about $10 \mathrm{sec}$ ) and scored the magnitude of their perceived efficacy on a 10-point scale, ranging from 0 ("cannot do it") to 10 ("certainly can do it"). The reliability coefficient (Cronbach's $\alpha$ ) of this questionnaire was 0.91 .

\section{Semistructured interviews}

In the second stage of the study, semistructured interviews were conducted to gather more information about the difficulties experienced by the students when solving problems in the numerical or symbolic format. The interview data were also used to investigate the impacts that different representational formats had on solving these problems from the perspectives of the students. The interview protocol can be seen in Appendix B.

Twelve students ( 6 females and 6 males) with different levels of prior knowledge-from either the numerical or symbolic group-participated in the second stage of the study. They first spent 20-25 min completing physics problems in a format that was different from those that they completed in stage 1, and they were then interviewed individually immediately after finishing the test. The interviewer prepared both the numerical and symbolic test papers that the interviewees had finished previously. The students were asked to illustrate and explain their responses to the two problem-solving tests for each question, and to compare the level of difficulty they encountered in the two formats (Appendix B). In addition, the interviews focused on how the students perceived these two representations and asked them to express how the numerical and symbolic representational formats influenced their problem-solving process. The interviews lasted for an average of $40 \mathrm{~min}$. All interviews were videotaped and then subsequently transcribed verbatim and analyzed.

\section{Data analysis}

Hypotheses 1-4 were tested using a two-way multivariate analysis of variance (MANOVA). The analysis was performed using SPSS software to identify the relations and interactions between the two independent variables (i.e., representational format and gender) and the two dependent variables (i.e., self-efficacy and problem-solving performance). Statistical parameters such as mean and SD values and effect sizes were also calculated to quantify differences between the numerical and symbolic groups and between genders.

For stage 2, the writing responses of 12 interviewees were classified into the 3 steps of problem solving and coded sequentially (Appendix A). Their performance in each step was coded using 3 levels according to the correctness and completeness of these responses: level 3, correct and complete answer (scored as 2 points); level 2, partially correct or partially complete answer (1 point); and level 1, incorrect or missing answer (0 points). A correct and complete answer (level 3 ) in the second step (planning the solution) should include the related physics principles, constraints, conditions, and equations or formulas required to solve this question; an example would be "Because the object is falling with the same velocity, all of the forces acting upon it are balanced. Newton's first law can apply to this condition" or "Newton's second law can be used in this situation. The formula is $F=m a$." The scoring rubrics, sample answers, and ideal solutions are presented in Appendix A.

There may be multiple approaches to solving a particular problem. Regardless of the approach that students took, we coded and analyzed their answers by applying the same criteria of correctness and completeness. Two coders who had majored in physics and science education independently analyzed the responses of six students, and achieved an interrater reliability coefficient of 0.82 .

After analyzing and coding all of the responses for the numerical and symbolic formats, we calculated the total scores for each problem-solving step (ranging from 0 to 12) for every interviewee. Then, to answer the second research question, a nonparametric within-subject analysis technique was employed to examine the differences in performance between the two formats in each step. Nonparametric tests (or distribution-free tests) use the median instead of the mean and are based on fewer assumptions (e.g., not assuming that the data are approximately normally distributed). This study applied nonparametric Wilcoxon tests for the within-subject comparisons to test hypothesis 5, because the sample of interview students was small and not normally distributed.

The third research question was answered by analyzing the interview transcripts. During the interviews, the interviewees described their ideas about the problem-solving process and explained why an isomorphic question posed using one format was more difficult than using the other. These responses were then coded using the procedures 
suggested by Strauss and Corbin [57] and Erickson [58]; the final coding scheme comprised two categories and eight subcategories. Finally, two researchers who had majored in science education independently coded half of the interview transcripts, which produced an interrater reliability coefficient of 0.80 .

\section{RESULTS}

\section{A. Effects of the representational format and gender on self-efficacy and problem-solving performance}

The Pearson correlation coefficient was calculated to examine the relationship between self-efficacy and the problem-solving performance of the students. The results revealed significant correlations between them regardless of the representational format (numerical: $r=0.60, p<$ 0.05 ; symbolic: $r=0.68, p<0.05$ ), which was consistent with the results of previous studies [33,52]. In addition, we confirmed the presence of significant correlations between self-efficacy and the midterm examination scores of the students (including the same physics concepts) (numerical: $r=0.43, p<0.05$; symbolic: $r=0.51, p<0.05$ ).

Significant correlations between self-efficacy and the performance of students were also found regardless of gender (girls: $r=0.54, p<0.05$; boys: $r=0.55, p<0.05$ ), which is similar to results in the literature [33,34]. Additionally, there were significant correlations between self-efficacy and midterm examination scores among both females $(r=0.47, p<0.05)$ and males $(r=0.49$, $p<0.05)$.

A 2 (representational format) $\times 2$ (gender) MANOVA was employed $[60,61]$ to test hypotheses $1-4$ simultaneously. This explored the influence of gender and representational format on the self-efficacy of students in solving physics problems and their performance. The descriptive statistics results are presented in Table III. First of all, Box's $M$ test, which examines the assumptions of homogeneity of variance-covariance matrices, produced satisfactory results (Box's $M=10.63, p=0.33$ ). Applying Wilks' criterion indicated that the combined dependent variables were significantly affected by both the representational format (Wilks' $\Lambda=0.68, p<0.05, \eta^{2}=0.32$ ) and gender (Wilks' $\Lambda=0.94, p<0.05, \eta^{2}=0.06$ ), but not by their interaction (Wilks' $\Lambda=0.99, p=0.51$ ).

A main effect of gender was found for the self-efficacy of students in solving physics problems $[F(1,96)=5.85$, MSE $\left.=391.57, p<0.05, \eta^{2}=0.06\right]$ (Table IV). Gender explained $6 \%$ of the variance in the self-efficacy of the students. In contrast, representational format had no significant effect $[F(1,96)=0.03, p=0.86]$. In other words, the male students had significantly higher self-efficacy when successfully solving physics problems $($ mean $=5.76$, $\mathrm{SD}=2.26$ ) than did their female counterparts (mean $=$ $4.74, \mathrm{SD}=1.97$ ), but their self-efficacy did not vary significantly with the representational format. These findings supported hypothesis 4 (boys having higher selfefficacy when solving problems than do girls), and refuted hypothesis 2 (higher self-efficacy when solving numerical than symbolic problems).

A main effect of the representational format on the problem-solving performance of the students was observed $\left[F(1,96)=26.46, \mathrm{MSE}=391.57, p<0.05, \eta^{2}=0.22\right]$. As indicated by the partial $\eta^{2}$ value, a considerable amount of the variance in performance (i.e., 22\%) was explained by the representational format. On the other hand, gender had no significant main effect on their performance $[F(1,96)=0.98, p=0.33]$. These results suggest that the numerical group (mean $=42.94, \mathrm{SD}=21.71$ ) significantly outperformed the symbolic group (mean $=22.37$, $\mathrm{SD}=17.25$ ) and that their problem-solving performance did not vary significantly with gender. Therefore, hypotheses 1 and 3 (better performance on numerical problems and no gender difference in problem-solving performance, respectively) were confirmed.

\section{B. Problem-solving processes of interviewees}

In order to answer the second research question and test hypothesis 5, we analyzed and coded the problem-solving processes of 12 interviewees in both numerical and symbolic tests. The responses of different levels in each problem-solving step for the two formats are showed in Table V and Fig. 3. The scores of every interviewee for the two formats in each problem-solving step were calculated, and a nonparametric within-subjects analysis was applied

TABLE IV. Results of MANOVA examining the effects of the representational format and gender on self-efficacy and problemsolving performance.

\begin{tabular}{|c|c|c|c|c|c|c|c|}
\hline Dependent variable & Source & SS & df & MS & $F$ & $p$ & $\eta^{2}$ \\
\hline \multirow[t]{3}{*}{ Self-efficacy } & Representational format & 0.14 & 1 & 0.14 & 0.03 & 0.86 & 0.00 \\
\hline & Gender & 26.24 & 1 & 26.24 & 5.85 & $<0.05^{\mathrm{a}}$ & 0.06 \\
\hline & Representational format $\times$ gender & 1.99 & 1 & 1.99 & 0.44 & 0.51 & 0.01 \\
\hline \multirow[t]{3}{*}{ Problem-solving performance } & Representational format & 10360.20 & 1 & 10360.20 & 26.46 & $<0.05^{\mathrm{a}}$ & 0.22 \\
\hline & Gender & 383.24 & 1 & 383.24 & 0.98 & 0.33 & 0.01 \\
\hline & Representational format $\times$ gender & 43.95 & 1 & 43.95 & 0.11 & 0.74 & 0.00 \\
\hline
\end{tabular}

\footnotetext{
${ }^{\mathrm{a}} p<0.05$
} 
TABLE V. The distribution of responses for the numerical and symbolic formats for each problem-solving step.

\begin{tabular}{|c|c|c|c|c|c|c|c|c|c|c|c|c|}
\hline \multirow{3}{*}{ Problem-solving step } & \multicolumn{4}{|c|}{ First step } & \multicolumn{4}{|c|}{ Second step } & \multicolumn{4}{|c|}{ Third step } \\
\hline & \multicolumn{4}{|c|}{ Describing the physics } & \multicolumn{4}{|c|}{ Planning the solution } & \multicolumn{4}{|c|}{ Executing the plan and evaluating solutions } \\
\hline & \multicolumn{2}{|c|}{ Numerical } & \multicolumn{2}{|c|}{ Symbolic } & \multicolumn{2}{|c|}{ Numerical } & \multicolumn{2}{|c|}{ Symbolic } & \multicolumn{2}{|c|}{ Numerical } & \multicolumn{2}{|c|}{ Symbolic } \\
\hline Formats & $n$ & $\%$ & $n$ & $\%$ & $n$ & $\%$ & $n$ & $\%$ & $n$ & $\%$ & $n$ & $\%$ \\
\hline Level 3 & $7^{\mathrm{b}}$ & $10^{\mathrm{c}}$ & 7 & 10 & 24 & 33 & 19 & 26 & 26 & 36 & 8 & 11 \\
\hline Level 2 & 32 & 44 & 26 & 36 & 20 & 28 & 20 & 28 & 16 & 22 & 15 & 21 \\
\hline Level 1 & 33 & 46 & 39 & 54 & 28 & 39 & 33 & 46 & 30 & 42 & 49 & 68 \\
\hline Sum & $72^{\mathrm{a}}$ & 100 & 72 & 100 & 72 & 100 & 72 & 100 & 72 & 100 & 72 & 100 \\
\hline
\end{tabular}

${ }^{\mathrm{a}}$ Twelve students participated in the second stage of the study and took a problem-solving test consisting of 6 questions, resulting in a total of 72 responses.

${ }^{\mathrm{b}}$ The coding number 7 means that in the first step, 7 numerical questions were classified as level 3.

${ }^{\mathrm{c}} 7 / 72$ (total numerical questions) $\cong 10 \%$.

to identify any significant differences between the two formats in each step in how the students performed (Table VI).

In the first step (describing the physics), $10 \%$ of the responses reached level 3 for each of the two formats, and about half of the questions were classified as level 1 (numerical: 46\%; symbolic: 54\%). A Wilcoxon signedranks test indicated that the descriptions of the physics written by the students did not differ markedly between the two representational formats $(Z=1.40, p=0.16)$.

In the second step (planning the solution), more responses were classified as a higher level for the numerical format than the symbolic one. However, the statistical analysis revealed no significant difference in the performance of the students in this step between the two formats $(Z=1.44, p=0.15)$.

In the third step (executing the plan and evaluating solutions), the students seemed to experience difficulties when facing symbolic problems, while for the numerical problems they were more capable of providing correct

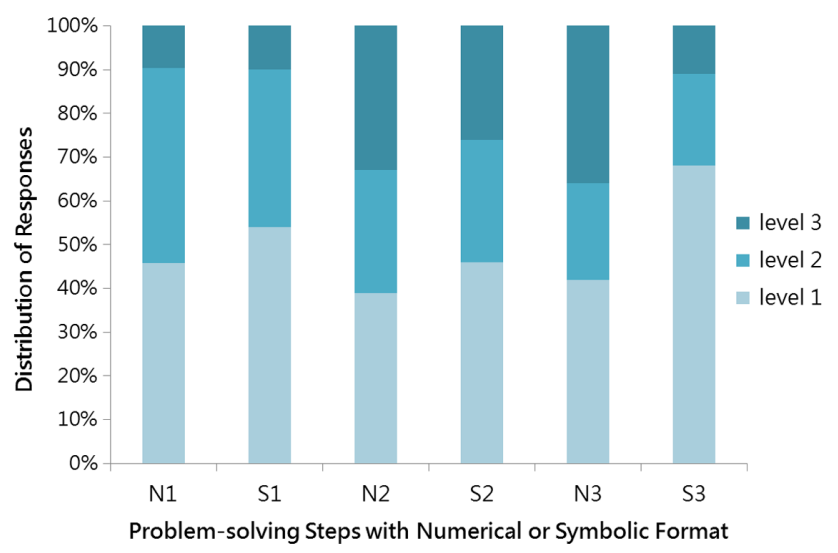

FIG. 3. Percentage of questions in three problem-solving steps for the numerical or symbolic format. $N 1$ represents the first step in the numerical format and $S 2$ represents the second step in the symbolic format. and complete answers (Fig. 3). In other words, the interviewees performed better on numerical problems $($ median $=12.5)$ than on symbolic ones $($ median $=8.5)$ $(Z=3.08, p<0.05, r=0.63)$. In summary, these results suggest that the difference in the students' performance for the two formats was enlarged through the problem-solving process and also vindicated hypothesis 5 .

\section{Perceptions of physics problems with different representational formats}

\section{Difficulties in solving numerical and symbolic problems}

The results of the analysis of the students' interview responses are presented in Table VII. The first category integrated how the interviewees perceived the degree of difficulty of solving numerical and symbolic problems. Overall, more students indicated that solving symbolic physics problems was more difficult than solving numerical ones, particularly in the first $(75.0 \%)$ and third (72.2\%) steps. As for planning the solution, most of the responses $(69.2 \%)$ showed that the degree of difficulty of the two formats was similar, while the others still indicated that planning the solution for symbolic problems was more difficult $(30.8 \%)$.

When the students were asked to compare the degree of difficulty of solving between numerical and symbolic problems, $45.5 \%$ of the responses indicated that solving numerical problems was as difficult as solving symbolic ones, $37.9 \%$ indicated that solving symbolic problems was more difficult, and $16.7 \%$ indicated that solving numerical problems was more difficult. Most of the students found that solving symbolic physics problems was more difficult than numerical ones across all three steps. During the interviews they also explained the reasons behind their answers. The coded responses including the impact of either the numerical or symbolic format are summarized in Table VII. 
TABLE VI. Differences in the problem-solving performance of students for the numerical and symbolic formats for each problemsolving step.

\begin{tabular}{|c|c|c|c|c|c|c|}
\hline \multirow{3}{*}{$\frac{\text { Problem-solving step }}{\text { Format }}$} & \multicolumn{2}{|c|}{ First step } & \multicolumn{2}{|c|}{ Second step } & \multicolumn{2}{|c|}{ Third step } \\
\hline & \multicolumn{2}{|c|}{ Describing the physics principles } & \multicolumn{2}{|c|}{ Planning the solution } & \multicolumn{2}{|c|}{ Executing the plan and evaluating the solution } \\
\hline & Numerical & Symbolic & Numerical & Symbolic & Numerical & Symbolic \\
\hline Participants $(n)$ & 12 & 12 & 12 & 12 & 12 & 12 \\
\hline Median & 3.5 & 3.0 & 4.5 & 5.5 & 6.5 & 2.5 \\
\hline $\mathrm{IQR}^{\mathrm{a}}$ & 3.0 & 2.0 & 6.0 & 5.0 & 8.0 & 5.0 \\
\hline$Z$ & \multirow{3}{*}{\multicolumn{2}{|c|}{$\begin{array}{l}-1.40 \\
0.16\end{array}$}} & \multicolumn{2}{|c|}{-1.44} & \multicolumn{2}{|c|}{-3.08} \\
\hline & & & \multicolumn{2}{|c|}{0.15} & \multicolumn{2}{|c|}{$<0.05$} \\
\hline Effect size $(r)$ & & & & & & \\
\hline
\end{tabular}

${ }^{\mathrm{a}} \mathrm{IQR}=$ interquartile range.

\section{Impacts of different representational formats on solving problems}

The second category in Table VII focuses on students' perceptions of impacts of the different representational formats on solving physics problems. The largest proportions of students mentioned the disadvantages of the symbolic format $(47.8 \%)$ and the advantages of using the numerical format $(39.7 \%)$ on solving physics problems. These results were in accordance with how the students performed when solving problems in this study, and moreover could provide

TABLE VII. Coding scheme and results of the interview transcripts.

\begin{tabular}{|c|c|c|c|}
\hline Category & Subcategory & Code & $\begin{array}{c}\text { Number and } \\
\text { percentage }\end{array}$ \\
\hline $\begin{array}{l}\text { Degree of difficulty when } \\
\text { solving numerical or } \\
\text { symbolic problems } \\
\left(n^{\mathrm{a}}=100\right)\end{array}$ & $\begin{array}{l}\text { Describing the physics } \\
\text { principles } \\
\quad(n=16,16.0 \%) \\
\text { Planning the solution } \\
\quad(n=13,13.0 \%) \\
\text { Executing the plan and } \\
\text { evaluating the solution } \\
\quad(n=11,11.0 \%) \\
\text { Each problem } \\
\quad(n=66,66.0 \%)\end{array}$ & $\begin{array}{l}\text { Numerical format is more difficult } \\
\text { Symbolic format is more difficult } \\
\text { The difference is only small } \\
\text { Numerical format is more difficult } \\
\text { Symbolic format is more difficult } \\
\text { The difference is only small } \\
\text { Numerical format is more difficult } \\
\text { Symbolic format is more difficult } \\
\text { The difference is only small } \\
\text { Numerical format is more difficult } \\
\text { Symbolic format is more difficult } \\
\text { The difference is only small }\end{array}$ & $\begin{array}{c}1(6.3 \%) \\
12(75.0 \%) \\
3(18.8 \%) \\
0(0 \%) \\
4(30.8 \%) \\
9(69.2 \%) \\
2(18.2 \%) \\
8(72.7 \%) \\
1(9.1 \%) \\
11(16.7 \%) \\
25(37.9 \%) \\
30(45.5 \%)\end{array}$ \\
\hline $\begin{array}{l}\text { Impact of either the } \\
\text { numerical or symbolic } \\
\text { format }(n=209)\end{array}$ & $\begin{array}{l}\text { Disadvantages of numerical } \\
\quad \text { format }(n=8,3.8 \%) \\
\text { Advantages of symbolic } \\
\quad \text { format }(n=18,8.6 \%) \\
\\
\text { Disadvantages of symbolic } \\
\quad \text { format }(n=100,47.8 \%)\end{array}$ & $\begin{array}{l}\text { Positive perceptions } \\
\text { Takes less time } \\
\text { More willing to solve problems } \\
\text { Familiar format } \\
\text { Easy to evaluate the solution } \\
\text { Clear and definite solution } \\
\text { Unusual or particularly large values } \\
\text { Can't remind me of related equations } \\
\text { Reminds me of related equations or formula } \\
\text { Simplifies the equations } \\
\text { Avoids interference from numbers } \\
\text { Negative perceptions } \\
\text { Difficult to solve problems and evaluate the } \\
\text { solution } \\
\text { Unfamiliar format } \\
\text { Do not understand the meaning of symbols } \\
\text { Not willing to solve problems }\end{array}$ & $\begin{aligned} 30 & (36.1 \%) \\
15 & (18.1 \%) \\
15 & (18.1 \%) \\
8 & (9.6 \%) \\
8 & (9.6 \%) \\
7 & (8.4 \%) \\
6 & (75.0 \%) \\
2 & (25.0 \%) \\
12 & (66.7 \%) \\
4 & (22.4 \%) \\
2 & (11.1 \%) \\
35 & (35.0 \%) \\
30 & (30.0 \%) \\
& \\
14 & (14.0 \%) \\
14 & (14.0 \%) \\
7 & (7.0 \%)\end{aligned}$ \\
\hline
\end{tabular}

${ }^{\mathrm{a}}$ The total number of responses in this category was 100.

${ }^{\mathrm{b}}$ Positive perceptions: easy to understand, clear, feeling at ease, comfortable, etc.

${ }^{\mathrm{c}}$ Negative perceptions: confusing, abstract, complex, unclear or difficult, lost patience with the problem, etc. 
possible explanations for the differences in the performance between the two formats.

With respect to physics problems in the numerical format, the students had positive perceptions; they spent less time on them and were more willing to solve them. Moreover, the students were more familiar with numerical problems, which often had clear and definite solutions that were easy for them to evaluate. However, some interviewees remarked that the numerical problems with unusual or particularly large values were difficult. Additionally, problems in this format did not remind them of related equations or formulas.

Symbolic problems triggered more negative perceptions compared to numerical problems. The students found it difficult to solve symbolic problems and evaluate the solutions-they were not familiar with the symbolic format, and often did not understand the meaning of the symbols and so were not willing to solve them.

\section{DISCUSSION AND CONCLUSION}

To accurately assess the understanding that students have of physics and to provide them with effective teaching, physics teachers and educational researchers need to pay attention to the learning challenges associated with different representational formats in problem solving. This study advances the current knowledge in the field by showing the impacts of numerical and symbolic representations on the self-efficacy, problem-solving performance, processes, and perceptions of students. The study has also revealed the relations between various factors and physics problemsolving performance, and how problem-solving processes differ with representational format.

\section{A. Difference in problem-solving performance between the two formats}

The study findings suggest that the representational format markedly affects the problem-solving performance of students, with them performing better for the numerical than the symbolic format when solving isomorphic physics problems. In stage 1, those students solving numerical problems significantly outperformed those solving symbolic problems. Moreover, the interview data revealed that the students performed significantly better on numerical problems than on symbolic problems in the final step of executing the plan and evaluating solutions.

Our qualitative data, statistical results, and the insight from previous research could provide explanations for why students are more successful at solving numerical than symbolic isomorphic problems. This study found that the third step (executing the plan and evaluating solutions) was a key process for distinguishing between how students performed for the two representations when they were solving physics problems. This step requires students to write the equations relating to the known and target unknown variables according to the second step, and calculate the value of the target unknown variable [62]. The third step is more dependent than the other two steps on the mathematical abilities of the students, and so an insufficient mathematical knowledge or skills in solving symbolic problems was probably responsible for the difference between the two formats.

In the written responses of the interviewees who solved both the numerical and symbolic problems, the proportion of no responses was higher when they tackled the symbolic problems. Also, many of the interviewees failed to finish the final step of the symbolic problems because they encountered difficulties calculating the algebraic equations that included numerous symbols. However, this study provides relatively weak evidence for the mathematics resources of the students, and so future research could explore how the prior knowledge about mathematics of students or the mathematics instruction they receive affects their problem-solving processes and performance in physics.

The results of this study are consistent with those of previous studies of mathematics education $[21,22,63]$. The students had negative perceptions of symbolic problems for reasons that included their unfamiliarity with the format, the greater cognitive load required to interpret the meaning of symbols, and having a reduced intention to solve the problems. In contrast, when they did not have to deal with unfamiliar symbols, the students felt that solving numerical problems took less time and became more accessible. Additionally, they probably assumed that a solution should be a number, so defining and evaluating the solution in a numerical format-as performed in the third stepwas easier for them. In general, students' perceptions of numerical and symbolic problems seem to support the view that they have prior schemas to solve numerical problems but not symbolic ones.

Another possible reason is the inability of the students to understand or translate between information in physics and mathematics contexts. When the students were solving a symbolic problem in this study, they had to extract the physics information from symbols and link this information to mathematics equations. Rittle-Johnson and Alibali [64] found an interplay between the conceptual and procedural knowledge of mathematics, which implies that the procedural knowledge about how to solve physics problems (probably including mathematics knowledge) could powerfully influence the conceptual understanding of students and their problem-solving performance in physics. In other words, students would perform worse when facing physics problems that require more-complex procedural knowledge (e.g., symbolic problems). This idea may also explain differences in the degree of difficulty between isomorphic problems that involved the same physics concept. It is therefore important to distinguish conceptual from procedural knowledge in physics, and so more research is 
required to clarify the relationship between these two types of knowledge in problem solving.

Other unanswered questions include how and to what degree the inability of students to translate information between the physics and mathematics contexts affects their problem-solving performance and use of strategies in physics. More research is needed to explore the details of the process and to find ways to reduce the difference in the problem-solving performance of students between the two formats.

\section{B. Self-efficacy, problem solving, and gender}

The data obtained in this study did not support hypothesis 2 (i.e., students have higher self-efficacy when solving numerical problems than symbolic ones). The difference in the problem-solving performance in the numerical and symbolic formats was not reflected in the self-efficacy of the students. According to Pajares and Miller [65], selfjudgments of students about their own competence may be less accurate when they are facing unfamiliar assessment forms. The 10th-grade participants in the present study had more experience in solving numerical than symbolic problems, and so basing their ability judgments on past experience probably resulted in them overestimating their ability to solve symbolic problems.

To distinguish the effects of one format on students' performance from another format, each test used in this study contained only questions in a single format. However, symbolic problems are often used together with numerical ones in the physics context in classroom settings. Students or their teachers may attribute the failure to solve a problem to an incorrect factor, such as confusing not understanding a physics concept with a format being unfamiliar. This confusion could result in not only students misjudging their self-efficacy, but also teachers misinterpreting the conceptual understanding of students.

We also found that compared to the result from selfefficacy questionnaires, the perception data were more consistent with how the students actually performed (e.g., more students mentioned that the symbolic format was more difficult). This may be because when students were unfamiliar with the problem format and asked to evaluate their capability to solve a given problem in a short time, they probably made the judgment based on steps 1 and 2. Only when students actually worked out the problems and engaged in the third step, they experienced different levels of difficulty in solving numerical and symbolic problems. The results from interview data are also consistent with this explanation. The performances of students did not show a significant difference between the two problem types until step 3 and the majority of students referred to the symbolic problems as more difficult ones. That is to say, the perception data were collected after students had completed both the numerical and symbolic problems, and they could make more accurate judgments of their capability to solve problems in different formats. It also reminds us of the limitation on gathering the selfefficacy data.

The problem-solving performance did not differ with gender. This is consistent with the claim made by Hyde and colleagues $[49,50]$, and demonstrates that similar difficulties are encountered during physics problem solving regardless of formats among both genders. However, female students exhibited significantly lower self-efficacy than males for physics problem solving. Previous studies found that the degree of gender difference in academic self-efficacy varies with content domain, type of task, and age of the students $[46,52,66]$. Studies focusing on the science and mathematics self-efficacy of middle and high-school students showed that females generally exhibited a lower degree of self-efficacy than their actual performance when compared to males, while females reported higher science and mathematical anxiety than their male counterparts [33,41,52]. It has been suggested that the lack of confidence and higher anxiety about mathematics and science among girls are probably responsible for their underachievement in these disciplines, particularly for high-achieving girls [52].

The sources of self-efficacy may explain the gender differences in the relationship between performance and self-efficacy. Britner and Pajares [41,67] and Britner $[41,67]$ indicated that mastery experiences were the only significant predictor of science self-efficacy among boys in middle or high school. On the one hand, not only their mastery experiences but also the social persuasions, vicarious experiences, and physiological states of girls $[39,40]$ could better predict their self-efficacy in science $[41,67]$. Zeldin and colleagues [68,69] found the same pattern for the sources of perceived self-efficacy of successful men and women in science, mathematics, and engineering. That is, for these men and women, the development of self-efficacy primarily relied on interpreting their ongoing achievements and on the relational episodes in their lives, respectively.

Some recent studies have examined the changes in the self-efficacy of males and females in physics after different teaching activities $[46,70]$ and between diverse relational networks [70]. These studies have provided some insights into how to detect and maintain the confidence that students have in their capability to learn physics. In order to improve girls' judgment of their capability and to support the learning of students of different genders [70], on the one hand, physics teachers and educators need to explore the relationships between gender, self-efficacy, and problemsolving performance in detail. On the other hand, they can search for suitable teaching activities and be aware of the different effects resulting in the change in the physics self-efficacy of the different genders.

\section{The problem-solving process}

In the first step only a relatively small proportion (10\%) of the students responses were complete and correct 
(level 3), with about half of the responses being classified as level 1. The results echoed findings from previous studies, which showed that students often ignored the construction of problem representations [30] or could not relate them to the mathematical part of the problem [2]. In contrast, experts such as physics teachers and physicists will commonly draw a diagram as an effective strategy for describing the physical situation when solving a problem [14]. In order to fill the gap between experienced problem solvers and novices, teachers need to illustrate the value of constructing diagrams, increase the use of them, and further bolster the confidence of students in using diagrams [30].

\section{Implications}

The interview data indicated that most of the students referred to the advantages of the numerical format and the disadvantages of the symbolic format when they were describing the effects caused by the different formats on problem solving. Teachers and researchers may consider to exploit these advantages of different representational formats and arrange or introduce the physics problems appropriately.

At the same time, the fact that a relatively large proportion of students' responses were associated with their subjective feelings and perceptions of the format (such as feeling familiar, strange, or more willing to solve it) also reminds us that students' perceptions of a problem are a crucial element significantly related to their behavior and performance $[52,56]$. Teachers and educators should pay attention to students' perceptions as they may provide some useful information about students' performance and achievement.

The results of this study have some instructional implications. For example, teachers need to consider the effects of different representations when they are examining how students understand physics concepts. Some studies have indicated that changing the sequence or combination of representations could affect the perceptions of students and in turn influence their learning and performance $[12,59,71,72]$. For example, a "concreteness fading (concrete-then-idealized)" approach can take the advantages of different types of representations to activate multiple schemas and further promote the transfer of complex scientific rules to a new context [72]. Thus, when teachers introduce new physics concepts or develop assessments, they should use appropriate representations (e.g., numerical then symbolic) to allow students to benefit from both formats. Teachers should also provide timing scaffolds (e.g., describing the meaning of symbols and converting symbolic into numerical questions) to establish meaningful links between numbers and symbols in order to meet the needs of students.

\section{APPENDIX A: SCORING RUBRICS FOR THE EXAMPLE PROBLEM IN TABLE I}

\section{Numerical problem}

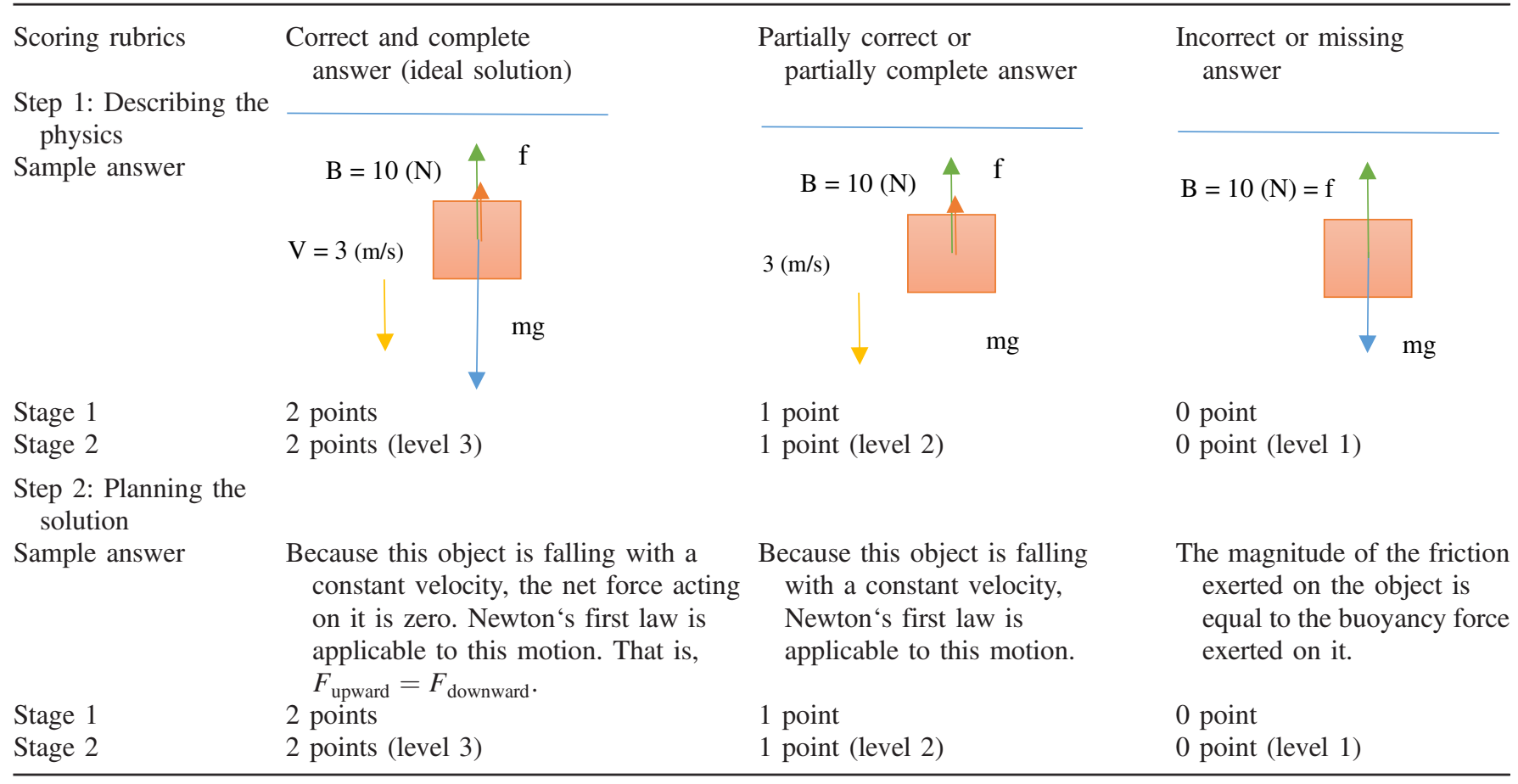

(Table continued) 


\section{Step 3: Executing the plan and evaluating solutions}

$\begin{array}{ll}\text { Sample answer } & B+f=W=\mathrm{mg} \\ & 10+f=3 \times 10 \\ & f=20(\mathrm{~N}) \\ \text { Stage 1 } & 6 \text { points } \\ \text { Stage 2 } & 2 \text { points (level 3) }\end{array}$

$10+f=3 \times 10$
$f=20(\mathrm{~kg})$
3 points
1 point (level 2)
$f=B=10(\mathrm{~N})$

0 point

0 point (level 1)

\section{Symbolic problem}

Scoring rubrics

Step 1: Describing the physics Sample answer

Stage 1

Stage 2

Step 2: Planning the solution Sample answer

Stage 1

Stage 2

Step 3: Executing the plan and evaluating solutions Sample answer

Stage 1

Stage 2
Correct and complete answer (ideal solution)

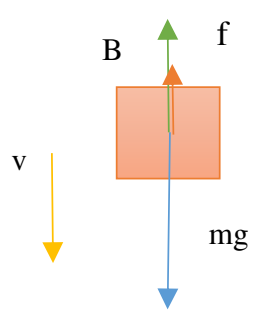

2 points

2 points (level 3)

Because this object is falling with a constant velocity, the net force acting on it is zero. Newton's first law is applicable to this motion. That is $F_{\text {upward }}=F_{\text {downward }}$. 2 points

2 points (level 3)

$B+f=W=\mathrm{mg}$

$f=\mathrm{mg}-B(N)$

6 points

2 points (level 3)
Partially correct or partially complete answer

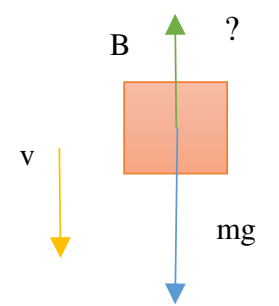

1 point

1 point (level 2)

Because this object is falling with a constant velocity, Newton's first law is applicable to this motion.

1 point

1 point (level 2)

$B+f=W=\mathrm{mg}$

3 points

1 point (level 2)
Incorrect or missing answer

$$
B=f
$$

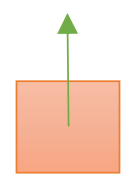

0 point

0 point (level 1)

The magnitude of the friction exerted on the object is equal to the buoyancy force exerted on it.

0 point

0 point (level 1)

$B=f(N)$

0 point

0 point (level 1)

\section{APPENDIX B: INTERVIEW PROTOCOL}

1. The problem-solving process consists of three steps. First is to describe the physics, the second step is planning the solution, and the third step is executing the plan and evaluatingsolutions. After you completed these two tests, the numerical and symbolic formats,

(1) Which kind of problem is more difficult in the first step (i.e., describing the physics)?

(2) Which kind of problem is more difficult in the second step (i.e., planning the solution?
(3) Which kind of problem is more difficult in the third step (i.e., executing the plan and evaluatingsolutions)?

2. Please make comparisons between a pair of questions in the numerical and symbolic formats. Which kind of problem is more difficult in this pair of questions? Please explain your reason in detail.

(Every interviewee was asked to answer the above question from the first to the sixth isomorphic pairs of physics questions.) 
[1] J. L. Docktor and J. P. Mestre, Synthesis of disciplinebased education research in physics, Phys. Rev. ST Phys. Educ. Res. 10, 020119 (2014).

[2] B. Ibrahim and N. S. Rebello, Representational task formats and problem solving strategies in kinematics and work, Phys. Rev. ST Phys. Educ. Res. 8, 010126 (2012).

[3] P. B. Kohl and N. D. Finkelstein, Effects of representation on students solving physics problems: A fine-grained characterization, Phys. Rev. ST Phys. Educ. Res. 2, 010106 (2006).

[4] P. B. Kohl and N. D. Finkelstein, Student representational competence and self-assessment when solving physics problems, Phys. Rev. ST Phys. Educ. Res. 1, 010104 (2005).

[5] D. E. Meltzer, Relation between students' problem-solving performance and representational format, Am. J. Phys. 73, 463 (2005).

[6] B. Hoffman and A. Spatariu, The influence of self-efficacy and metacognitive prompting on math problem-solving efficiency, Contemp. Educ. Psychol. 33, 875 (2008).

[7] R. R. Cadmus Jr., A video technique to facilitate the visualization of physical phenomena, Am. J. Phys. 58, 397 (1990).

[8] S. Ainsworth, The functions of multiple representations, Comput. Educ. 33, 131 (1999).

[9] L. T. Escalada, and D. A. Zollman, An investigation on the effects of using interactive digital video in a physics classroom on student learning and attitudes, J. Res. Sci. Teach. 34, 467 (1997).

[10] M. De Cock, Representation use, and strategy choice in physics problem solving, Phys. Rev. ST Phys. Educ. Res. 8, 020117 (2012).

[11] P. B. Kohl and N. D. Finkelstein, Patterns of multiple representation use by experts and novices during physics problem solving, Phys. Rev. ST Phys. Educ. Res. 4, 010111 (2008).

[12] R. Moreno, G. Ozogul, and M. Reisslein, Teaching with concrete and abstract visual representations: Effects on students' problem solving, problem representations, and learning perceptions, J. Educ. Psychol. 103, 32 (2011).

[13] K. R. Koedinger and M. J. Nathan, The real story behind story problems: Effects of representations on quantitative reasoning, J. Learn. Sci. 13, 129 (2004).

[14] L. N. Walsh, R. G. Howard, and B. Bowe, Phenomenographic study of students' problem solving approaches in physics, Phys. Rev. ST Phys. Educ. Res. 3, 020108 (2007).

[15] J. Tuminaro, A Cognitive Framework for Analyzing and Describing Introductory Students' Use and Understanding of Mathematics in Physics, Ph.D. dissertation (Maryland University, College Part, MD, 2003), http://www.physics .umd.edu/perg/dissertations/Tuminaro/.

[16] J. Tuminaro and E. F. Redish, Elements of a cognitive model of physics problem solving: Epistemic games, Phys. Rev. ST Phys. Educ. Res. 3, 020101 (2007).

[17] H.-K. Wu and S. Puntambekar, Pedagogical affordances of multiple external representations in scientific processes, J. Sci. Educ. Technol. 21, 754 (2012).

[18] E. F. Redish, Problem Solving and the Use of Math in Physics Courses, in Proceedings of the World View on
Physics Education in 2005: Focusing on Change, (Delhi, 2005) [arXiv:physics/0608268v1].

[19] E. F. Redish and E. Kuo, Language of physics, language of math: Disciplinary culture and dynamic epistemology, Sci. Educ. 24, 561 (2015).

[20] J. Tuminaro and E. F. Redish, Understanding students' poor performance on mathematical problem solving in physics, AIP Conf. Proc. 720, 113 (2004).

[21] L. R. Booth, Children's difficulties in beginning algebra, in The Ideas of Algebra, K-12, edited by A. F. Coxford and A. P. Shulte (National Council of Teachers of Mathematics, Reston, VA, 1988), p. 20.

[22] J. Lucariello, M. T. Tine, and C. M. Ganley, A formative assessment of students' algebraic variable misconceptions, J. Math. Behav. 33, 30 (2014).

[23] N. Herscovics and L. Linchevski, A cognitive gap between arithmetic and algebra, Educ. Stud. Math. 27, 59 (1994).

[24] J. Sweller, Cognitive load theory, learning difficulty, and instructional design, Learn. Instr. 4, 295 (1994).

[25] A. Newell and H. A. Simon, Human Problem Solving (Prentice-Hall, Englewood Cliffs, 1972).

[26] T. J. Nokes, C. D. Schunn, and M. T. Chi, Problem solving and human expertise, International Encyclopedia of Education (Elsevier Ltd., New York, 2010).

[27] D. Hammer, A. Elby, R. E. Scherr, and E. F. Redish, Resources, framing, and transfer, in Transfer of Learning from a Modern Multidisciplinary Perspective, edited by J. Mestre (Information Age Publishing, Greenwich, CT, 2005), p. 89.

[28] T. Ben-Zeev, Rational errors and the mathematical mind, Rev. Gen. Psychol. 2, 366 (1998).

[29] P. Heller and M. Hollabaugh, Teaching problem solving through cooperative grouping. Part 2: Designing problems and structuring groups, Am. J. Phys. 60, 637 (1992).

[30] Y. Uesaka, E. Manalo, and S. I. Ichikawa, What kinds of perceptions and daily learning behaviors promote students' use of diagrams in mathematics problem solving?, Learn. Instr. 17, 322 (2007).

[31] E. T. Torigoe and G. E. Gladding, Connecting symbolic difficulties with failure in physics, Am. J. Phys. 79, 133 (2011).

[32] A. Bandura, Guide for constructing self-efficacy scales, in Self-efficacy beliefs of adolescents, edited by T. Urdan and F. Pajares (Information Age Publishing, Greenwich, CT, 2006), p. 307.

[33] F. Pajares, Self-efficacy beliefs in academic settings, Rev. Educ. Res. 66, 543 (1996).

[34] B. J. Zimmerman, Self-efficacy: An essential motive to learn, Contemp. Educ. Psychol. 25, 82 (2000).

[35] B. Hoffman, "I think I can, but I'm afraid to try": The role of self-efficacy beliefs and mathematics anxiety in mathematics problem-solving efficiency, Learn. Indiv. Differ. 20, 276 (2010).

[36] B. Hoffman and G. Schraw, The influence of self-efficacy and working memory capacity on problem-solving efficiency, Learn. Indiv. Differ. 19, 91 (2009).

[37] F. Pajares and M.D. Miller, Role of self-efficacy and self-concept beliefs in mathematical problem solving: A path analysis, J. Educ. Psychol. 86, 193 (1994). 
[38] S. Çalışkan, G. S. Selçuk, and M. Erol, Instruction of problem solving strategies: Effects on physics achievement and self-efficacy beliefs, J. Baltic Sci. Educ. 9, 20 (2010).

[39] A. Bandura, Social Foundations of Thought and Action: A Social Cognitive Theory (Prentice-Hall, Inc., Englewood Cliffs, 1986).

[40] A. Bandura, Self-Efficacy: The Exercise of Self-Control (Freeman, New York, 1997).

[41] S. L. Britner and F. Pajares, Sources of science self-efficacy beliefs of middle school students, J. Res. Sci. Teach. 43, 485 (2006).

[42] A. M. Cavallo, W. H. Potter, and M. Rozman, Gender differences in learning constructs, shifts in learning constructs, and their relationship to course achievement in a structured inquiry, yearlong college physics course for life science majors, School Sci. Math. 104, 288 (2004).

[43] S. L. Eddy and S. E. Brownell, Beneath the numbers: A review of gender disparities in undergraduate education across science, technology, engineering, and math disciplines, Phys. Rev. Phys. Educ. Res. 12, 020106 (2016).

[44] A. M. Kelly, Social cognitive perspective of gender disparities in undergraduate physics, Phys. Rev. Phys. Educ. Res. 12, 020116 (2016).

[45] K. L. Lewis, J. G. Stout, S. J. Pollock, N. D. Finkelstein, and T. A. Ito, Fitting in or opting out: A review of key social-psychological factors influencing a sense of belonging for women in physics, Phys. Rev. Phys. Educ. Res. 12, 020110 (2016).

[46] J. M. Nissen and J. T. Shemwell, Gender, experience, and self-efficacy in introductory physics, Phys. Rev. Phys. Educ. Res. 12, 020105 (2016).

[47] L. E. Kost, S. J. Pollock, and N. D. Finkelstein, Characterizing the gender gap in introductory physics, Phys. Rev. ST Phys. Educ. Res. 5, 010101 (2009).

[48] A. Madsen, S. B. McKagan, and E. C. Sayre, Gender gap on concept inventories in physics: What is consistent, what is inconsistent, and what factors influence the gap?, Phys. Rev. ST Phys. Educ. Res. 9, 020121 (2013).

[49] J. S. Hyde and M. C. Linn, Gender similarities in mathematics and science, Science 314, 599 (2006).

[50] J. S. Hyde, S. M. Lindberg, M. C. Linn, A. B. Ellis, and C. C. Williams, Gender similarities characterize math performance, Science 321, 494 (2008).

[51] OECD, PISA 2015 Results (Volume I): Excellence and Equity in Education (Summary) (OECD Publishing, Paris, 2016).

[52] OECD, The ABC of Gender Equality in Education: Aptitude, Behaviour, Confidence, PISA (OECD Publishing, Paris, 2015).

[53] N. M. Else-Quest, J. S. Hyde, and M. C. Linn, Crossnational patterns of gender differences in mathematics: A meta-analysis, Psychol. Bull. 136, 103 (2010).

[54] Organisation for Economic Co-operation and Development (OECD), PISA 2012 results: Ready to learn: Students' engagement, drive and self-beliefs (Vol. III): Preliminary version (OECD, Paris, 2013).

[55] R. Owston, D. York, and S. Murtha, Student perceptions and achievement in a university blended learning strategic initiative, Internet High. Educ. 18, 38 (2013).
[56] M.-T. Wang and R. Holcombe, Adolescents' perceptions of school environment, engagement, and academic achievement in middle school, Am. Educ. Res. J. 47, 633 (2010).

[57] A. Strauss and J. Corbin, Basics of Qualitative Research: Procedures and Techniques for Developing Grounded Theory (Sage, Thousand Oaks, 1998).

[58] F. Erickson, Qualitative research methods for science education, Second International Handbook of Science Education (Springer, New York, 2012), pp. 1451-1469.

[59] C. Singh, Assessing student expertise in introductory physics with isomorphic problems. II. Effect of some potential factors on problem solving and transfer, Phys. Rev. ST Phys. Educ. Res. 4, 010105 (2008).

[60] H. Keselman, C. J. Huberty, L. M. Lix, S. Olejnik, R. A. Cribbie, B. Donahue, R. K. Kowalchuk, L. L. Lowman, M. D. Petoskey, and J. C. Keselman, Statistical practices of educational researchers: An analysis of their ANOVA, MANOVA, and ANCOVA analyses, Rev. Educ. Res. 68, 350 (1998).

[61] B. G. Tabachnick and L.S. Fidell, Using Multivariate Statistics (Allyn and Bacon, Boston, 2007).

[62] D. Huffman, Effect of explicit problem solving instruction on high school students' problem-solving performance and conceptual understanding of physics, J. Res. Sci. Teach. 34, 551 (1997).

[63] L. Linchevski, Algebra with numbers and arithmetic with letters: A definition of pre-algebra, J. Math. Behav. 14, 113 (1995).

[64] B. Rittle-Johnson and M. W. Alibali, Conceptual and procedural knowledge of mathematics: Does one lead to the other?, J. Educ. Psychol. 91, 175 (1999).

[65] F. Pajares and M. D. Miller, Mathematics self-efficacy and mathematical problem solving: Implications of using different forms of assessment, J. Exp. Educ. 65, 213 (1997).

[66] C. Huang, Gender differences in academic self-efficacy: A meta-analysis, Eur. J. Psychol. Educ. 28, 1 (2013).

[67] S. L. Britner, Motivation in high school science students: A comparison of gender differences in life, physical, and earth science classes, J. Res. Sci. Teach. 45, 955 (2008).

[68] A. L. Zeldin and F. Pajares, Against the odds: Selfefficacy beliefs of women in mathematical, scientific, and technological careers, Am. Educ. Res. J. 37, 215 (2000).

[69] A. L. Zeldin, S. L. Britner, and F. Pajares, A comparative study of the self-efficacy beliefs of successful men and women in mathematics, science, and technology careers, J. Res. Sci. Teach. 45, 1036 (2008).

[70] R. Dou, E. Brewe, J. P. Zwolak, G. Potvin, E. A. Williams, and L. H. Kramer, Beyond performance metrics: Examining a decrease in students' physics self-efficacy through a social networks lens, Phys. Rev. Phys. Educ. Res. 12, 020124 (2016).

[71] H.-K. Wu, Y.-F. Lin, and Y.-S. Hsu, Effects of representation sequences and spatial ability on students' scientific understandings about the mechanism of breathing, Instr. Sci. 41, 555 (2013).

[72] R. L. Goldstone and J. Y. Son, The transfer of scientific principles using concrete and idealized simulations, J. Learn. Sci. 14, 69 (2005). 